\title{
Berberine reduces the expression of adipogenic enzymes and inflammatory molecules of 3T3-L1 adipocyte
}

\author{
Bong-Hyuk Choi ${ }^{1}$, In-Sook Ahn ${ }^{1}$, \\ Yu-Hee Kim ${ }^{1}$, Ji-Won Park', \\ So-Young Lee ${ }^{1}$, Chang-Kee Hyun ${ }^{1}$ \\ and Myoung-Sool Do, \\ ${ }^{1}$ School of Life and Food Sciences \\ Handong Global University \\ Pohang 791-708, Korea \\ ${ }^{2}$ Corresponding author: Tel, 82-54-260-1301; \\ Fax, 82-54-260-1306; E-mail, msdo@handong.edu
}

Accepted 21 September 2006

Abbreviations: ACC, acetyl-CoA carboxylase; ACS, acyl-CoA synthase; BBR, berberine; BCS, bovine calf serum; C/EBP- $\alpha$, CCAAT/enhancer binding protein-alpha; COX, cyclooxygenase; CRP, C-reactive protein; FAS, fatty-acid synthase; HP, haptoglobin; HSL, hormone-sensitive lipase; LPL, lipoprotein lipase; MCP-1, monocyte chemoattractant protein-1; PPAR- $\gamma$, peroxisome proliferator-activated receptor-gamma; SCAP, SREBP cleavage-activating protein; SREBP-1c, sterol regulatory element binding proteins-1c; TG, triglyceride

\begin{abstract}
Berberine (BBR), an isoquinoline alkaloid, has a wide range of pharmacological effects, yet its exact mechanism is unknown. In order to understand the anti-adipogenic effect of BBR, we studied the change of expression of several adipogenic enzymes of 3T3-L1 cells by BBR treatment. First, we measured the change of leptin and glycerol in the medium of 3T3-L1 cells treated with $1 \mu \mathrm{M}, 5 \mu \mathrm{M}$ and $10 \mu \mathrm{M}$ concentrations of BBR. We also measured the changes of adipogenic and lipolytic factors of 3T3-L1. In 3T3-L1 cells, both leptin and adipogenic factors (SREBP-1c, C/EBP- $\alpha$, PPAR- $\gamma$, fatty acid synthase, acetyl-CoA carboxylase, acyl-CoA synthase and lipoprotein lipase) were reduced by BBR treatment. Glycerol secretion was increased, whereas expression of lipolytic enzymes (hormone-sensitive lipase and perilipin) mRNA was slightly decreased. Next, we measured the change of inflammation markers of 3T3-L1 cells by BBR treatment. This resulted in the down-regulation of mRNA level of inflammation markers such as TNF- $\alpha$, IL-6, Creactive protein and haptoglobin. Taken together, our
\end{abstract}

data shows that BBR has both anti-adipogenic and anti-inflammatory effects on 3T3-L1 adipocytes, and the anti-adipogenic effect seems to be due to the down-regulation of adipogenic enzymes and trans cription factors.

Keywords: adipocytes; berberine; inflammation; lipoprotein lipase; PPAR- $\gamma$; tumor necrosis factor- $\alpha$

\section{Introduction}

Berberine (BBR) is an isoquinoline derivative alkaloid isolated from many medicinal herbs, such as Hydrastis Canadensis (goldenseal), Cortex phellodendri (Huangbai) and Rhizoma coptidis (Huanglian) (Ikram, 1975). Studies have shown that BBR, the major component of these herbs, has many pharmacological effects including inhibition of adipocyte differentiation, anti-cancer effects, anti-microbial effects, LDL-lowering effects and anti-inflammatory potential (Amin, 1969; Huang and Williams, 1999; Anis et al., 2001; Zhou, 2003; Kong et al., 2004; Kuo et al., 2004). But the role of BBR in inhibition of adipocyte differentiation and the mechanism of anti-inflammatory activity have not yet been clarified.

Recently, there has been a rapid increase of studies in adipocytes along with the increasing incidence of obesity. Adipose tissue is now recognized as a major endocrine and secretory organ, releasing a wide range of protein factors and signals termed adipokines. Leptin, which is mainly secreted by adipocytes, regulates appetites and energy metabolism in human and rodents (Cuellar et al., 2001; Kim et al., 2003).

Differentiation of fibroblasts into adipose tissue requires several transcription factors such as SREBP1c, C/EBP $-\alpha$ and PPAR- $\gamma$. SREBP-1C is strongly associated with SCAP and these complexes are divided into two parts by insulin action or sterol concentration. Then activated SREBP-1c accelerates adipogenesis through the overexpression of adipogenic enzymes such as FAS, ACC and ACS. These factors alone cannot promote differentiation of non-adipogenic fibroblasts, but when coexpressed on fibroblasts expressing PPAR- $\gamma$, cell differentiation is enhanced (Kim, et al., 1998). PPAR- $\gamma$ appears to function as both a direct regulator of many fatspecific genes and also as a "master" regulator that can trigger the entire program of adipogenesis 
(Spiegelman and Flier, 1996). LPL is the major enzyme which hydrolyzes TG molecules of chylomicrons and VLDL particles. The released free fatty acids are either oxidized to generate ATP in muscle or stored in adipose tissue (Auwerx et al., 1992). On the other hand, there are several enzymes which have lipolytic function in adipose tissue. HSL is commonly known to be the rate-limiting enzyme of lipolysis. Activation of, or overexpression of, HSL prevents TG accumulation in adipocytes (Sztalryd et al., 1995). Perilipins, which are phosphoproteins coating the surfaces of lipid droplets of adipocytes, have been postulated to modulate HSL activity (Martinez-Botas et al., 2000).

It has also been known that adipose tissue produces and secretes inflammatory factors such as TNF- $\alpha$, IL- 6, CRP and HP. Most of them are elevated in proportion to adiposity. Studies have also shown that such increases of inflammatory cytokines are related to metabolic diseases such as diabetes mellitus. Therefore obesity is known to be associated with a chronic and low-grade inflammatory state.

The aim of this study is to investigate whether BBR has anti-adipogenic and anti-inflammatory effects in 3T3-L1 cells. For this purpose, we measured leptin and glycerol levels to examine the reduction of fat accumulation, and also measured mRNA expression of adipogenic transcription factors, adipogenic enzymes and lipolytic enzymes. We also examined the mRNA expression of inflammation-related adipokines using real time RT-PCR.

\section{Materials and Methods}

\section{T3-L1 adipocyte culture and treatment of sample}

Mouse 3T3-L1 pre-adipocytes were grown to confluence in DMEM with $10 \% \mathrm{BCS}$ at $37^{\circ} \mathrm{C}$ in a humidified atmosphere of $5 \% \quad \mathrm{CO}_{2}$. At 1 day postconfluence (designated "day 0"), cell differentiation was induced with a mixture of methylisobutylxanthine $(0.5 \mathrm{mM})$, dexamethasone $(0.25 \mu \mathrm{M})$, and insulin $(5 \mu \mathrm{g} / \mathrm{ml})$ in DMEM containing $10 \% \mathrm{FBS}$. On day 2 and thereafter, DMEM containing 10\% FBS and insulin $(5 \mu \mathrm{g} / \mathrm{ml})$ only was subsequently replaced every 2 days.

BBR was dissolved in DMSO, divided into small quantities, and stored in $-20^{\circ} \mathrm{C}$. At day 8 , after inducing differentiation of adipocytes, the sample was dissolved in DMEM at $1 \mu \mathrm{M}, 5 \mu \mathrm{M}$ and $10 \mu \mathrm{M}$ concentrations, which were treated into adipocytes for $18 \mathrm{~h}$ (Kong, 2004). The final concentration of DMSO was less than $0.1 \%$. After treating the samples for $18 \mathrm{~h}$, the medium was collected for analysis of leptin and glycerol. Cells were used for
RNA extraction, as described below.

\section{Measurement of leptin by ELISA}

Measurement of leptin was performed with a sandwich ELISA. Anti-mouse leptin, recombinant mouse leptin, and biotinylated anti-mouse leptin antibodies were purchased from R\&D Systems (Minneapolis, $\mathrm{MN}$ ) and followed protocol.

\section{Measurement of glycerol}

Glycerol levels were determined using the enzymatic reagent, free glycerol reagent (Sigma, St. Luis MO), directed by the protocol of GPO-TRINDER (Sigma, St. Luis, MO).

\section{Measurement of intracellular TG contents}

The accumulation of triglyceride was measured by Oil Red O staining. To investigate the effect of BBR on triglyceride levels during adipocyte differentiation, cultured adipocytes were fixed with $10 \%$ fresh Formalin (Sigma). They were rinsed in phosphate buffered saline (Biowhittaker) and incubated in filtered Oil-Red-O staining solution (Sigma) at $4^{\circ} \mathrm{C}$ for $1 \mathrm{~h}$. After the staining solution was removed, the dye retained in the cells was eluted into isopropanol and $\mathrm{OD}_{540}$ was determined (Chae and Kwak, 2003). Total protein was determined by Bradford assay.

\section{RNA extraction and cDNA synthesis}

Total RNA was isolated from 3T3-L1 adipocytes using Trizol reagent (Invitrogen, Carlsbad, CA). First strand cDNA synthesis was performed with $2 \mu \mathrm{g}$ of total RNA using Superscript II reverse transcriptase (BD bioscience, Palo Alto, CA).

\section{Real-time RT-PCR}

In a florescent temperature cycler (LightCycler; Roche Diagnostics Ltd, Lewes, UK), ten percent of each RT reaction was amplified in a $20 \mu \mathrm{l}$ PCR containing $4 \mathrm{mM} \mathrm{MgCl}_{2}, 4 \mathrm{pM}$ each primer and $1 \times$ LightCycler DNA Master SYBR Green 1 mix (Roche Diagnostics Ltd, Lewes, UK). Samples were incubated in the LightCycler for an initial denaturation at $94^{\circ} \mathrm{C}$ for $30 \mathrm{~s}$, followed by $40 \mathrm{PCR}$ cycles. Each cycle consisted of $95^{\circ} \mathrm{C}$ for $10 \mathrm{~s}, 60^{\circ} \mathrm{C}$ for $5 \mathrm{~s}$, and $72^{\circ} \mathrm{C}$ for $12 \mathrm{~s}$. The oligonucleotide primers for the experiment are indicated in Table 1. To confirm amplification of specific transcripts, melting curve profiles (cooling the sample to $65^{\circ} \mathrm{C}$ for $15 \mathrm{~s}$ and heating slowly to $95^{\circ} \mathrm{C}$ with continuous measurement of fluorescence) were produced at the end of each PCR. 
Table 1. Gene specific primer used for RT-PCR.

\begin{tabular}{|c|c|c|c|}
\hline Gene name & Accession No. & & Sequence \\
\hline \multirow[t]{2}{*}{ SREBP-1c } & BC056922 & Forward & 5'-AAT GGT CCA GGC AAG TTC TGG GT-3' \\
\hline & & Reverse & 5'-TCC CTC TCA GCT GTG GTG GTG AA-3' \\
\hline \multirow[t]{2}{*}{ C/EBP- $\alpha$} & NM_007678 & Forward & 5'-TGC TGG AGT TGA CCA GTG AC-3' \\
\hline & & Reverse & 5'-AAA CCA TCC TCT GGG TCT CC-3' \\
\hline \multirow[t]{2}{*}{ PPAR- $\gamma$} & NM_011146 & Forward & 5'-TTT TCA AGG GTG CCA GTT TCA ATC C-3' \\
\hline & & Reverse & 5'-AAT CCT TGG CCC TCT GAG AT-3' \\
\hline \multirow[t]{2}{*}{ ACS } & NM_007981 & Forward & 5'-TGA CCT CTC CAT GCA GTC AG-3' \\
\hline & & Reverse & 5'-GAG CCT ATG CAC TCA GCC AGT-3' \\
\hline \multirow[t]{2}{*}{ ACC } & AY451393 & Forward & 5'-GAG TGA CTG CCG AAA CAT CTC TG-3' \\
\hline & & Reverse & 5'-GCC TCT TCC TGA CAA ACG AGT-3' \\
\hline \multirow[t]{2}{*}{ FAS } & NM_007988 & Forward & 5'-TGG GTT CTA GCC AGC AGA GT-3' \\
\hline & & Reverse & 5'-TAC CAC CAG AGA CCG TTA TGC-3' \\
\hline \multirow[t]{2}{*}{ LPL } & BC003305 & Forward & 5'-GCC CAG CAA CAT TAT CCA GT-3' \\
\hline & & Reverse & 5'-GGT CAG ACT TCC TGC TAC GC-3' \\
\hline \multirow[t]{2}{*}{ HSL } & BC021642 & Forward & 5'-AGA CAC CAG CCA ACG GAT AC-3' \\
\hline & & Reverse & 5'-CAT CAC CCT CGA AGA AGA GCA-3' \\
\hline \multirow[t]{2}{*}{ Perilipin } & NM_175640 & Forward & 5'-CTC TGG GAA GCA TCG AGA AG-3' \\
\hline & & Reverse & 5'-GCA TGG TGT GTC GAG AAA GA-3' \\
\hline \multirow[t]{2}{*}{ IL-6 } & NM_031168 & Forward & 5'-AGT TGC CTT CTT GGG ACT GAT-3' \\
\hline & & Reverse & 5'-TCC ACG ATT TCC CAG AGA AC-3' \\
\hline \multirow[t]{2}{*}{ CRP } & NM_007768 & Forward & 5'-GGG TGG TGC TGA AGT ACG AT-3' \\
\hline & & Reverse & 5'-CCA AAG ACT GCT TTG CAT CA-3' \\
\hline \multirow[t]{2}{*}{ TNF- $\alpha$} & AK078708 & Forward & 5'-AGG CCT TGT GTT GTG TTT CCA-3' \\
\hline & & Reverse & 5'-ATG GGG GAC AGC TTC CTT CTT-3' \\
\hline \multirow[t]{2}{*}{$\mathrm{HP}$} & NM_017370 & Forward & 5'-GAG AGG TCC ACG ATG AGA GCC-3' \\
\hline & & Reverse & 5'-CCT TCG GCC CGT AGT CTG TAG-3' \\
\hline \multirow[t]{2}{*}{$\beta$-actin } & NM_007393 & Forward & 5'-AGC CAT GTA CGT AGC CAT CC-3' \\
\hline & & Reverse & 5'-TCC CTC TCA GCT GTG GTG GTG AA-3' \\
\hline
\end{tabular}

\section{Statistical analysis}

The data was analyzed by the ANOVA procedure of Statistical Analysis System (SAS Institute, 19992001). Significant differences between groups were determined using Duncan's multiple range tests at the $P<0.05$ level.

\section{Results}

\section{Effect of BBR on leptin and glycerol secretion and} intracellular TG contents

We treated the fully differentiated 3T3-L1 adipocytes with $1 \mu \mathrm{M}, 5 \mu \mathrm{M}$, and $10 \mu \mathrm{M}$ concentrations of BBR in order to measure the change of leptin secretion. BBR, except in $1 \mu \mathrm{M}$ concentrations, reduced leptin secretion of $3 \mathrm{~T} 3-\mathrm{L} 1$ adipocytes by $61 \%$ and $75 \%$, respectively (Figure 1A). Glycerol levels in the medium after treatment with BBR were also measured.
Figure 1B shows that glycerol secretion decreased in $1 \mu \mathrm{M}, 5 \mu \mathrm{M}$ and $10 \mu \mathrm{M}$ concentrations of BBR by $3 \%, 41 \%$ and $48 \%$, respectively. BBR-treated $3 T 3-$ $\mathrm{L} 1$ adipocytes had reduced levels of intracellular TG contents compared with untreated cells by $8 \%$ respectively (Figure 1C).

\section{Effect of BBR on mRNA expression of adipogenic factors}

In order to know whether reduction of leptin secretion is caused by inhibition of adipogenic mechanism, we examined the expression level of mRNA of adipogenic transcription factors, SREBP1c, C/EBP- $\alpha$ and PPAR- $\gamma$, in 3T3-L1 treated by 10 $\mu \mathrm{M}$ of BBR by real-time RT-PCR. Figure $2 A$ shows that SREBP-1C, C/EBP- $\alpha$ and PPAR- $\gamma$ mRNA levels are decreased by $40 \%, 22 \%$ and $65 \%$, respectively. We also measured the change of adipogenic enzy- 
A

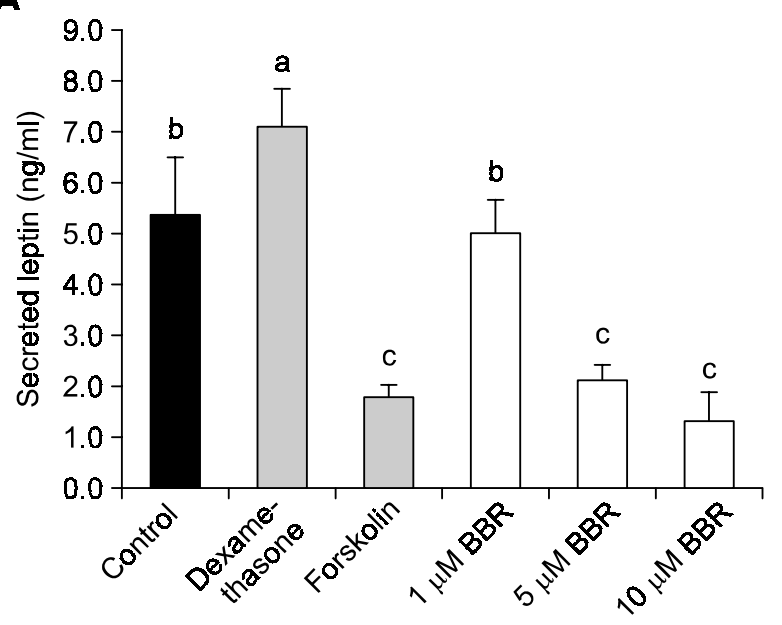

C

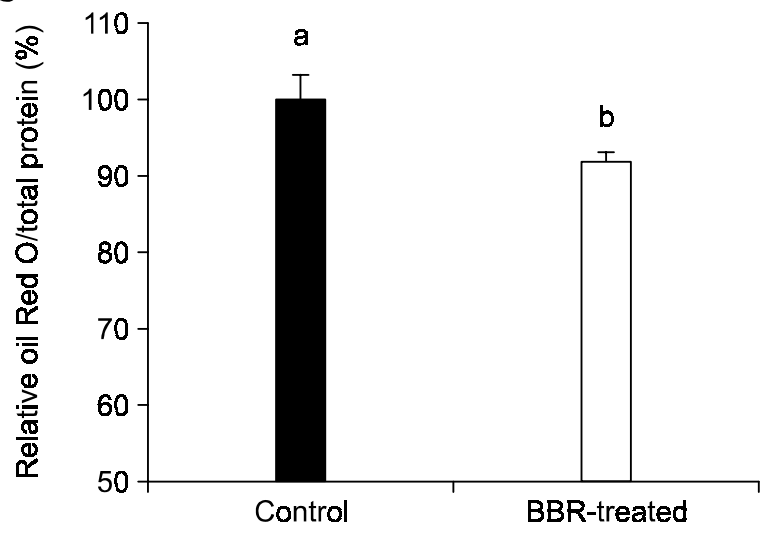

mes, such as FAS, ACC and ACS by real-time RT-PCR. The mRNA levels of FAS, ACC and ACS are decreased by $63 \%, 45 \%$ and $50 \%$, respectively (Figure 2B). LPL expression is not directly associated with lipid synthesis but strongly associated with adipogenesis. Therefore, we measured the expression level of LPL mRNA, and found that the level of expression in BBR treated 3T3-L1 cells was also reduced by $72 \%$ compared to that of the untreated cells (Figure 2B).

\section{Effect of BBR on mRNA expression of lipolytic enzymes}

We have shown that BBR treatment decreased the glycerol secretion in 3T3-L1 cells in Figure 1B, which was not consistent with the result of leptin data. We also measured mRNA levels of lipolytic enzymes, such as HSL and perilipin. HSL and perilipin mRNA levels are slightly increased by $8 \%$ and $8 \%$ respectively (Figure 2C).

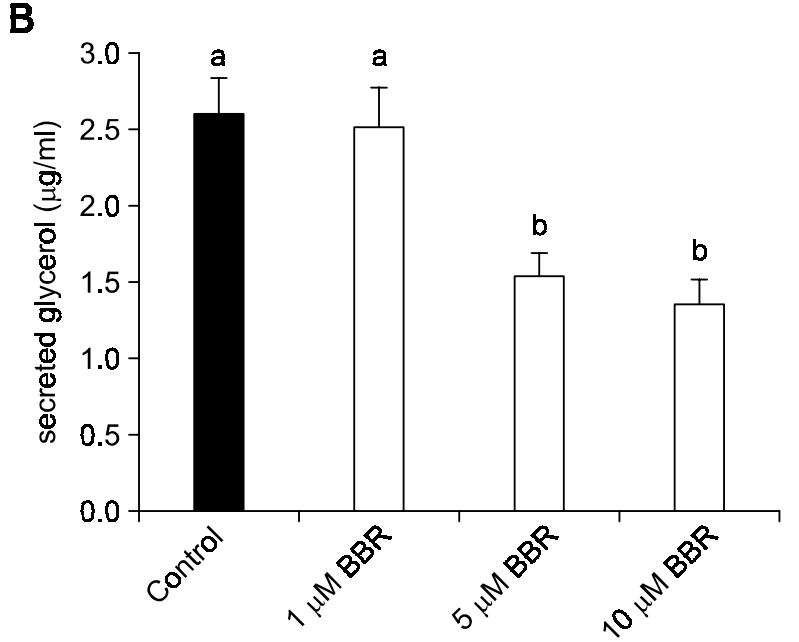

Figure 1. Effects of BBR on the secretion of leptin and glycerol level and intracellular TG contents. 3T3-L1 cells were treated with various concentrations of BBR. (A) Leptin secretion. Adipocytes were treated with vehicle alone (control), dexamethasone (positive control), forskolin (negative control) and various concentrations of BBR. Leptin secretion was quantified by ELISA. (B) Glycerol secretion. Adipocytes were cultured with or without BBR. Media were harvested for glycerol measurement. (C) Intracellular TG contents. Adipocytes were cultured with $(10 \mu \mathrm{M})$ or without BBR. Intracellular TG contents were quantified by Oil Red $O$ staining. Each bar represents mean $\pm \operatorname{S.E}(n=3)$ from three independent experiments. Means with different letters are significantly different $(P<0.05)$ by Duncan's multiple range test.

\section{Effect of BBR on mRNA expression of inflammatory cytokines}

We have examined the effect of BBR on inflammatory markers in 3T3-L1 adipocytes. The mRNA expressions of TNF- $\alpha$, IL-6, CRP and HP were estimated by real time RT-PCR. BBR reduced the mRNA expression level of inflammation factors such as TNF- $\alpha$, IL- 6, CRP and HP. The mRNA expression level of HP is most significantly reduced by BBR treatments among these. The mRNA expression levels of other inflammatory factor are decreased by $39 \%, 17 \%$ and $19 \%$, respectively (Figure 3 ).

\section{Discussion}

In this study we have tested the secretion level of leptin and glycerol in BBR treated fully differentiated 3T3-L1 adipocytes. We have shown that BBR reduces secretion of leptin and glycerol in 3T3-L1 adipocytes. The low secretion level of glycerol is not an expected result because it was thought that 
A
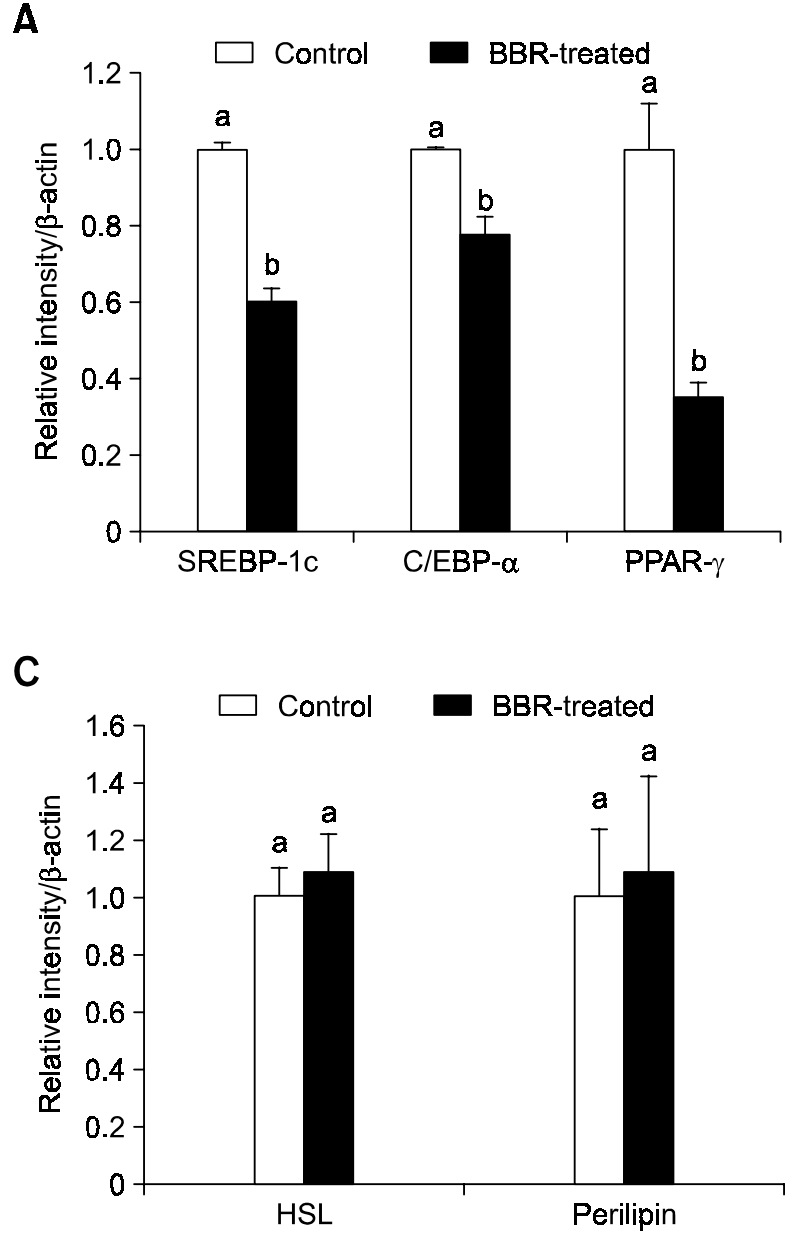

adipocyte reducing effects are caused by lipolysis. And we also have verified that the expression level of lipolytic enzyme mRNA such as HSL and perilipin was slightly increased by BBR-treatment, but not significantly. From this data we could assume that the effects of BBR on the reduction of adipocytes are not owed to lipolysis. However, the level of HSL and perilipin mRNA expression does not indicate the results of lipolysis precisely, because these lipolytic enzymes are activated by phosphorylation. Therefore, we need to investigate the degree of phosphorylation of HSL and perilipin after BBR treatment to know more detailed mechanisms in 3T3-L1 adipocytes.

These results prompted us to examine the possibility that BBR treatment may reduce adipogenic factors such as adipogenic transcription factors and enzymes. So we have investigated the mRNA expression levels of adipogenic factors, including SREBP-1c, C/EBP- $\alpha$, PPAR- $\gamma$, FAS, ACC and ACS, by real-time RT-PCR. As we expected, the mRNA levels of both transcription factors (SREBP-1C, C/EBP- $\alpha$, and PPAR- $\gamma$ ) and enzymes (FAS, ACC

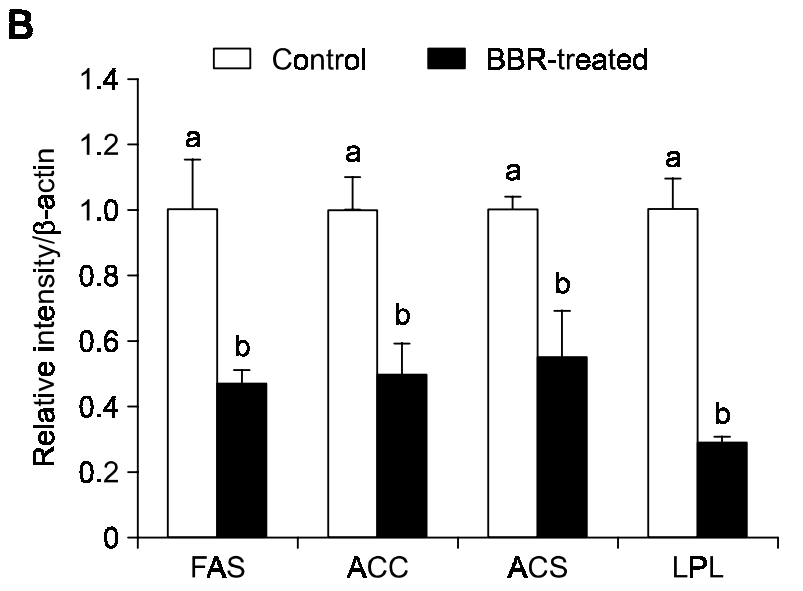

Figure 2. mRNA expressions of adipogenic transcription factors, adipogenic enzymes and lipolytic enzymes in BBR-treated 3T3-L1 adipocyte. At day 8 after inducing differentiation, adipocytes were cultured in 6-well plates with or without BBR for $18 \mathrm{~h}$. Graphs represent mRNA expression of (A) adipogenic transcription factors such as SREBP-1c, C/EBP- $\alpha$, PPAR- $\gamma$ and (B) adipogenic enzymes such as ACC, ACS, FAS and LPL and (C) lipolytic enzymes such as HSL, perilipin. Data are expressed relative to untreated control cells and represent means \pm S.E. Experiments were conducted twice, each included triplication. Means with different letters are significantly different $(P<0.05)$ by Duncan's multiple range test.

and $A C S$ ) associated with adipocyte differentiation were decreased by BBR treatment (Figure 2A and $2 \mathrm{~B})$. These results indicate that BBR down-regulates the adipogenic enzymes and finally decreases the amount of leptin secretion. Furthermore, the levels of transcription factors, especially PPAR- $\gamma$, which regulate the adipogenic enzymes, were also down-regulated. Thus we were able to conclude that BBR decreases the production of adipocytes by regulating the expression levels of adipogenic transcription factors in an adipocyte differentiation program.

LPL is the major enzyme for hydrolysis of circulating TG-rich lipoproteins. It is associated with the entering of free fatty-acids into the adipocytes by break-down of circulating chylomicrons, but does not have a direct effect on adipocyte differentiation. In other studies, it has been reported that the mRNA expression level of LPL is increased by PPAR- $\gamma$ during adipocyte differentiation (Auwerx et al., 1992; Schoonjans et al., 1996) so we tested whether the mRNA expression level of LPL is decreased by BBR treatment. The mRNA expression level of $L P L$ is 


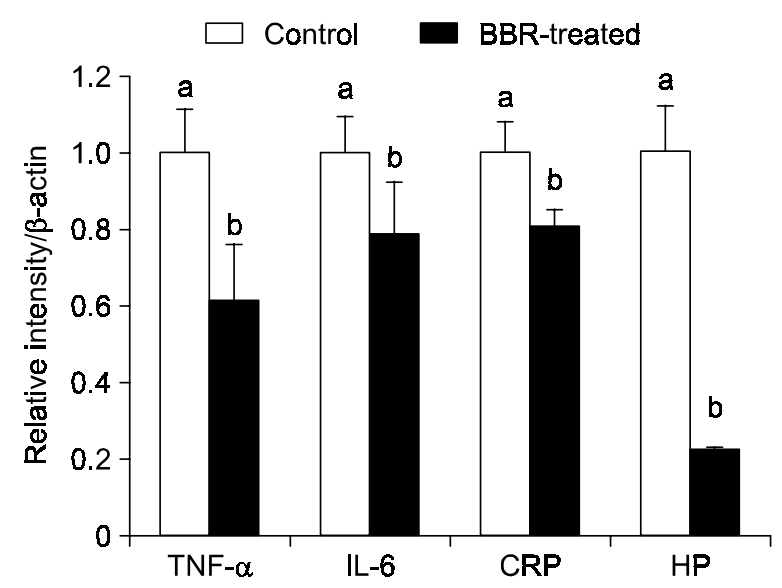

Figure 3. mRNA expressions of inflammatory cytokines and acutephase protein in BBR-treated 3T3-L1 adipocyte. At day 8 after inducing differentiation, adipocytes were cultured in 6-well plates with or without BBR for $18 \mathrm{~h}$. Graphs represent mRNA expression of inflammatory cytokines and acute-phase protein such as TNF- $\alpha$, IL- 6, CRP and HP. Data are expressed relative to untreated control cells and represent means \pm S.E. Experiments were conducted twice, each included triplication. Means with different letters are significantly different $(P<$ 0.05 ) by Duncan's multiple range test.

significantly decreased by $72 \%$ in BBR-treated cells and this result is caused by the reduced expression level of PPAR- $\gamma$ and TNF- $\alpha$ (Yang et al., 2002). Based on this data, we assumed that the reduced secretion levels of leptin and glycerol in 3T3-L1 adipocyte might be caused by reducing adipogenesis rather than the increasing effects of lipolytic activity. Likewise, the reduced expression level of PPAR- $\gamma$ is influenced by the mRNA expression level of LPL; hence the results of leptin and glycerol are due to the reduced expression level of LPL.

As we discussed earlier, adipocytes secrete various inflammatory molecules, which are conjectured and investigated to be related with obesity, diabetes and metabolic diseases. Because BBR has an adipocyte reducing effect, we hypothesized that BBR treatment may reduce the mRNA expression levels of adipocyte-secreted inflammatory molecules. So we investigated the mRNA expression levels of pro-inflammatory cytokines such as TNF- $\alpha$, IL-6, CRP and HP, and found that all of them are significantly reduced in BBR-treated 3T3-L1 adipocytes. These results allow us to conclude that BBR has inhibitory effects on adipocyte differentiation mechanisms as well as adipocyte-secreted inflammatory molecules. Recently, in other studies, many researchers are making their efforts to link obesity and inflammation. According to these researches, one of the most spotlighted molecules is leptin which is secreted by adipocyte specifically. Some articles reported that leptin upregulates MCP-1 secretion in human hepatic stellate cells. Moreover, leptin administration increases MCP-1 expression and hepatic inflammation during acute liver damage in vivo. In the same manner, reduced MCP-1 expression and liver inflammation were observed in leptin-deficient mice (Aleffi et al., 2005). And leptin has its effects on immune system. Since it belongs to $\mathrm{Ig}$ superfamily, leptin-mediated inflammation is activated by complement system (Otero et al., 2006). In addition, C/EBP family which is expressed during adipocyte differentiation is also associated with inflammation. Because both TNF- $\alpha$ and IL-6 have C/EBP binding site on their promoter regions, their expression levels are regulated by C/EBP family, including C/EBP- $\alpha, C / E B P-\beta$ and C/EBP- $\delta$ (Akira et al., 1990; Pope et al., 1994). In other studies, BBR has an anti-inflammatory effect by stimulating COX-2 expression in human oral epidermoid cancer cells (Kuo et al., 2004). Because COX2 plays a key role in prostaglandins synthesis, which is elevated in inflammation, it would be meaningful to investigate the change of COX level and activity by BBR treatment in adipocytes. Taken together, our results suggest that treatment of BBR both reduces the amount of adipose tissue by the means of suppressing adipogenesis and decreases the amount of inflammatory molecules.

\section{References}

Akira S, Isshiki $\mathrm{H}$, Sugita T, Tanabe O, Kinoshita S, Nishio Y, Nakajima T, Hirano T, Kishimoto T. A nuclear factor for IL-6 expression (NF-IL6) is a member of a C/EBP family. EMBO J 1990;9:1897-906

Aleffi S, Petrai I, Bertolani C, Parola M, Colombatto S, Novo E, Vizzutti F, Anania FA, Milani S, Rombouts K, Laffi G, Pinzani $M$, Marra F. Upregulation of proinflammatory and proangiogenic cytokines by leptin in human hepatic stellate cells. Hepatology 2005;42:1339-48

Amin $\mathrm{AH}$. Berberine sulfate: antimicrobial activity, bioassay, and mode of action. Can J Microbiol 1969;15:1067-76

Anis KV, Rajeshkumar NV, Kuttan R. Inhibition of chemical carcinogenesis by berberine in rats and mice. J Pharm Pharmacol 2001;53:763-8

Auwerx J, Leroy P, Schoonjans K. Lipoprotein lipase: recent contributions from molecular biology. Crit Rev Clin Lab Sci 1992;29:243-68

Chae GN, Kwak SJ. NF-kappaB is involved in the TNF-alpha induced inhibition of the differentiation of $3 T 3-L 1$ cells by reducing PPARgamma expression. Exp Mol Med 2003;35:431-7

Cuellar MJ, Giner RM, Recio MC, Manez S, Rios JL. Topical anti-inflammatory activity of some Asian medicinal plants used in dermatological disorders. Fitoterapia 2001;72:221-9

Huang KC, Williams WM. Antibacterial, antiviral, and 
antifungal herbs. In The pharmacology of Chinese Herbs. 1999, 381-3, CRC Press, New York, NY

Ikram M. A review on the chemical and pharmacological aspects of genus Berberis. Planta Med 1975;28:353-8

Kim JB, Sarraf P, Wright M, Mueller E, Lowell BB, Spiegelman $B M$. Nutritional and insulin regulation of fatty acid synthetase and leptin gene expression through ADD1/SREBP1. J Clin Invest 1998;101:1-9

Kim KH, Ahn SC, Lee MS, Kweon OS, Oh WK, Kim MS, Sohn $\mathrm{CB}$, Ahn JS. Adipocyte differentiation inhibitor isolated from the Barks of Phellodendron amurense. Korean J Food Sci Technol 2003;35:503-9

Kong W, Wei J, Abidi P, Lin M, Inaba S, Li C, Wang Y, Wang Z, Si S, Pan H, Wang S, Wu J, Wang Y, Li Z, Liu J, Jiang JD. Berberine is a novel cholesterol-lowering drug working through a unique mechanism distinct from statins. Nat Med 2004;10:1344-51

Kuo CL, Chi CW, Liu TY. The anti-inflammatory potential of berberine in vitro and in vivo. Cancer Letter 2004;203:127-37

Martinez-Botas J, Anderson JB, Tessier D, Lapillonne A, Chang BH, Quast MJ, Gorenstein D, Chen KH, Chan L. Absence of perilipin results in leanness and reverses obesity in Lepr (db/db) mice. Nat Genet 2000; 26:474-9
Otero M, Lago R, Gomez R, Dieguez C, Lago F, Gomez-Reino J, Gualillo O. Towards a pro-inflammatory and immunomodulatory emerging role of leptin. Rheumatology (Oxford) 2006;23:1-7

Pope RM, Leutz A, Ness SA. C/EBP beta regulation of the tumor necrosis factor-alpha gene. J Clin Invest 1994;94: 1449-55

Schoonjans K, Peinado-Onsurbe J, Lefebvre AM, Heyman RA, Briggs M, Deeb S, Staels B, Auwerx J. PPARalpha and PPARgamma activators direct a distinct tissue-specific transcriptional response via a PPRE in the lipoprotein lipase gene. EMBO J 1996;15:5336-48

Spiegelman BM, Flier JS. Adipogenesis and obesity: rounding out the big picture. Cell 1996;87:377-89

Sztalryd C, Komaromy MC, Kraemer FB. Overexpression of hormone-sensitive lipase prevents triglyceride accumulation in adipocytes. J Clin Invest 1995;95:2652-61

Yang JY, Koo BS, Kang MK, Rho HW, Sohn HS, Jhee EC, Park JW. Retinoic acid inhibits inducible nitric oxide synthase expression in 3T3-L1 adipocytes. Exp Mol Med 2002;34: 353-60

Zhou LB. Effect of berberine on the differentiation of adipocyte. Zhonghua Yi Xue Za Zhi 2003;83:338-40 